\title{
MANAJEMEN BANQUET DALAM MENANGANI EVENT WEDDING DI HOTEL PANGERAN BEACH KOTA PADANG
}

\author{
Alby Alfaro, Ira Meirina Chair \\ Progam Studi D4 Manajemen Perhotelan \\ Jurusan Pariwisata \\ Fakultas Pariwisata dan Perhotelan Universitas Negeri Padang \\ Email:albi.alfaro10@gmail.com
}

\begin{abstract}
Abstrak. This research is motivated by the condition of banquet management in handling wedding events at Pangeran Beach Hotel, Padang City, this can be seen from the lack of planning before the wedding event. This study aims to describe Banquet Management in Handling Event Weddings at Pangeran Beach Hotel, Padang City which includes: (a) Research, (b) Making Design, (c) Planning, (d) Coordination, (e) Evaluation.This research is a descriptive study with qualitative data. The types of data used are primary data and secondary data. Data collection techniques used were interview, observation, and documentation methods involving: Management of Pangeran Beach Hotel, Padang City, data analysis techniques used were qualitative data analysis.From the results of the study found several things related to banquet management in handling wedding events at Pangeran Beach Hotel, Padang City, namely: 1) The hotel does not have any planning regarding Research, organizing tasks and responsibilities of the Hotel, actions regarding Research are also absent, and there is also no supervision regarding research. 2) planning on event design is only carried out by consumers, the Hotel is not responsible for determining the design of the event, the Hotel action on event design only prepares the needs and demands of consumers, supervision of event design is only requested by the Sales marketing Hotel. 3) Planning in determining the time and place of the wedding is only planned by the consumer but regarding the work team has been well planned by the hotel, organizing tasks and responsibilities regarding the formation of work teams has been done well from the hotel, actions in determining the work team have been running with good and the supervision of the work team has been well implemented. 4) Planning regarding coordination has been well planned, organizing tasks and responsibilities has been going well, actions regarding the participation of each department have been implemented properly and supervision of each department leader has been carried out. 5) Planning the evaluation after the wedding event has been well planned by each hotel department, organizing the duties and responsibilities of each leader has been well implemented, the actions of the leadership of each department have been carried out properly and supervision in conducting evaluations has been well done.
\end{abstract}

Keywords: Management, Banquet, Event Wedding

\section{PENDAHULUAN}

Pariwisata merupakan sektor usaha yang cukup diandalkan di Indonesia, sektor usaha pariwisata menghasilkan devisa yang cukup tinggi untuk mendorong pembangunan di Indonesia. . Salah satu industri pariwisata yang sangat penting adalah hotel. Menurut Rumekso (2001: 17), "Hotel adalah bentuk bangunan yang menyediakan kamar-kamar untuk menginap, makanan dan minuman serta fasilitas lain yang diperlukan dan dikelola secara profesional untuk mendapatkan keuntungan bagi perusahaan itu sendiri". Hotel terdiri dari beberapa departemen salah satunya adalah departemen Food and Beverage. 
Departemen Food and Beverage memiliki beberapa bagian atau section, salah satunya adalah Banquet. Menurut pendapat Riyadi (2015: 180), "Banquet adalah salah satu bagian dari hotel yang tidak hanya menyediakan makanan dan minuman, mengatur dan merencanakan sebuah acara mulai dari ruangan yang akan digunakan, perlengkapan yang diperlukan serta hal-hal lain yang menunjang acara tersebut sesuai dengan keinginan yang mempunyai acara". Oleh sebab itu, untuk menagani sebuah acara atau event maka dibutuhkan manajemen yang baik dalam menanganinya.

Manajemen sangat penting untuk sebuah industri Hotel. Menurut George R. Terry dalam Tanti Prastuti (2014: 21), "Ada empat fungsi manajemen yang dikenal dengan "POAC" yaitu: a. Perencanaan (planning), b. Pengorganisasian (organizing), c. Pelaksanaan (actuating) dan d. Pengawasan (controlling). Berdasarkan pendapat diatas maka dapat disimpulkan ada empat fungsi manajemen diantaranya adalah perencanaan, pengorganisasian, pelakasanaan dan pengawasan.

Berdasarkan hasil pengamatan yang penulis lakukan selama melaksanakan kegiatan Pengalaman Industri di Hotel Pangeran Beach Kota Padang pada bulan Agustus sampai dengan Desember 2017, penulis mengetahui bahwa Hotel Pangeran Beach seringkali ramai dalam kegiatan acara seperti pernikahan atau wedding. Menurut Goldbart (2002:36-55) ada empat proses tahapan dalam penyelenggaraan sebuah event. Tahapan-tahapan tersebut adalah sebagai berikut: 1) Melakukan riset, 2) Membuat desain, 3) Melakukan planning atau perencanaan, 4) Melakukan koordinasi, dan 5) Evaluasi.

\section{METODE PENELITIAN}

Penelitian ini berjenis penelitian deskriptif dengan data kualitatif dengan metode survei. Sesuai dengan yang dikemukakan oleh Arikunto (2007: 234) bahwa, "Penelitian deskriftif adalah penelitian yang dimaksud untuk mengumpulkan informasi mengenai status gejala yang ada, yaitu gejala menurut apa adanya pada saat penelitian dilakukan". Penentuan informan yang akan diwawancarai dilakukan secara purposive sampling yaitu dipilih dengan pertimbangan dan tujuan tertentu.

Instrumen penelitian yang digunakan dalam penelitian ini adalah peneliti sendiri dengan menggunakan alat bantu berupa panduan waawancara, panduan observasi dan pengambilan dokumentasi.

Sesuai dengan permasalahan penelitian dan pendapat para ahli maka, penelitian ini bertujuan untuk memberikan gambaran, melihat, mengumpulkan pendapat dan mengungkapkan bagaimana manajemen banquet dalam menangani event wedding di Hotel Pangeran Beach Kota Padang. Rancangan penelitian ini melibatkan 1 variabel yaitu event dilihat dari 5 dimensi yaitu Riset, Desain event, Planning, Coordination, dan Evaluation dengan analisis POAC ( Planning, Organizing, Actuating, dan Controling).

\section{HASIL DAN PEMBAHASAN \\ Deskripsi Manajemen Riset}

Hasil penelitian terhadap manajemen banquet dalam menangani event wedding di Hotel Pangeran Beach Kota Padang memunculkan fakta bahwa perencanaan mengenai penelitian kebutuhan, harapan, dan keinginan konsumen dibidang ini pihak hotel tidak melaksanakan proses riset, untuk pengorganisasian tugas dan tanggung jawab mengenai riset setiap departemen hotel yang terlibat dalam pelaksanaan event wedding tidak 
memiliki tanggung jawab dalam melakukan riset, dan pengawasan terkait kebutuhan, harapan dan keinginan konsumen event wedding hanya dilakukan oleh pihak pimpinan Sales marketing ketika tamu sudah memesan wedding di Hotel Pangeran Beach. Akan tetapi yang menjadi masalah apabila pihak Hotel tidak melakukan riset kebutuhan, harapan, dan keinginan tamu terkait event wedding pihak Hotel tidak akan mengetahui mengenai bagaimana Trend yang sedang terjadi dan akan menjadi kelemahan untuk bersaing dengan Hotel-hotel yang ada di Kota Padang. Hal ini tidak sesuai dengan pendapat Goldbart (2002:36-55), "Riset dilakukan untuk menemukan kebutuhan, keinginan, dan harapan dari konsumen. Melalui riset, penyelenggara dapat melihat trend yang sedang berkembang dan dapat diimplementasikan dalam perencanaan event".

\section{Deskripsi Manajemen Membuat Desain}

Hasil penelitian terhadap manajemen banquet dalam menangani event wedding di Hotel Pangeran Beach Kota Padang memunculkan fakta bahwa perencanaan dalam menentukan tema, konsep, dekorasi serta hiburan ini hanya direncanakan oleh tamu wedding, pengorganisasian tugas dan tanggung jawab dari pihak Hotel tidak ada menentukan tema, konsep, dekorasi serta hiburan event wedding, dalam pelaksanaanya setiap departemen seperti banquet, housekeeping, dan engineering hanya mempersiapkan kebutuhan permintaan tamu event wedding tetap sebagai pelaksana saja juga tidak ikut menentukan tema, konsep, dekorasi serta hiburan event wedding dan pengawasan dalam hal ini hanya dilakukan oleh pihak Sales marketing Hotel. Hal ini sesuai dengan pendapat Goldbart (2002:36-55), "Membuat desain event adalah proses kelanjutan dari proses riset yang sudah dilakukan, hal ini dimulai dengan melakukan brainstorming untuk menentukan tema, konsep, dekorasi serta hiburan apa saja yang akan disajikan dan diterapkan dalam sebuah event".

\section{Deskripsi Manajemen Planning}

Hasil penelitian terhadap manajemen banquet dalam menangani event wedding di Hotel Pangeran Beach Kota Padang memunculkan fakta bahwa perencanaan dalam menentukan waktu dan tempat wedding hanya direncanakan oleh tamu wedding akan tetapi mengenai tim kerja pihak hotel ada sudah merencanakan sebaik mungkin, pengorganisasian tugas dan tanggung jawab dari pihak hotel sudah berjalan dengan baik mengenai pembentukan tim kerja, pengawasan dari pimpinan sendiri mengenai tim kerja sudah dilaksanakan dengan baik. Hal ini sesuai dengan pendapat Goldbart (2002:36-55), "Planning dilakukan setelah riset dan bersamaan dengan tahapan desain event. Tahapan ini penyelenggara event mulai melakukan beberapa hal, diantaranya adalah menentukan waktu yang dipakai untuk melakukan kegiatan, pemilihan tempat, menentukan tim kerja dan sebagainya".

\section{Deskripsi Manajemen Coordination}

Hasil penelitian terhadap manajemen banquet dalam menangani event wedding di Hotel Pangeran Beach Kota Padang memunculkan fakta bahwa perencanaan dalam bidang manajemen coordination ini sendiri sudah direncanakan dengan baik, pengorganisasian tugas dan tanggung jawab sudah berjalan dengan baik, tindakan mengenai partisipasi setiap departemen sudah dilaksanakan dengan baik dan pengawasan dari setiap pimpinan departemen Hotel sudah dilaksanakan. Hal ini sesuai dengan pendapat Goldbart (2002:36-55), "Melakukan koordinasi dengan pihak-pihak lain agar dapat bekerja secara simultan dengan satu tujuan yang sama". 


\section{Deskripsi Manajemen Evaluation}

Hasil penelitian terhadap manajemen banquet dalam menangani event wedding di Hotel Pangeran Beach Kota Padang memunculkan fakta bahwa perencanaan evaluasi setelah event wedding sudah direncanakan dengan baik, pengorganisasian tugas dan tanggung jawab setiap pimpinan departemen dalam melakukan evaluasi sudah dilaksanakan, tindakan pimpinan setiap departemen dalam melakukan evaluasi setelah event wedding sudah dijalankan dengan baik dan pengawasan dalam melakukan evaluasi ada dilakukan dalam setiap departemen yang berhubungan dengan pelaksanaan event wedding. Hal ini sesuai dengan pendapat Goldbart (2002:36-55), "Evaluation adalah proses evaluasi yang dilakukan untuk mengetahui apakah event yang diselenggarakan telah memenuhi atau menghasilkan tujuan sasaran yang telah ditentukan dalam perencanaan awal".

\section{SIMPULAN DAN SARAN \\ Simpulan}

Disimpulkan bahwa penerapan manajamen banquet dalam menangani event wedding di Hotel Pangeran Beach Kota Padang mengenai riset secara umum dapat dikategorikan kurang baik hal ini terlihat dari perencanaan di bidang Riset kebutuhan, harapan, dan keinginan konsumen dibidang ini pihak hotel tidak ada melakukan perencanaan, pengorganisasian tugas dan tanggung jawab setiap departemen hotel tidak memiliki tanggung jawab dalam melakukan riset, dan pengawasan dalam membuat desain hanya dilakukan oleh pihak pimpinan Sales marketing ketika tamu sudah memesan wedding di Hotel Pangeran Beach.

Disimpulkan bahwa penerapan manajamen banquet dalam menangani event wedding di Hotel Pangeran Beach Kota Padang mengenai membuat desain secara umum dapat dikategorikan kurang baik hal ini terlihat dari Pihak Hotel tidak bertanggung jawab dalam menentukan kebutuhan, harapan, dan keinginan tamu event wedding ,Tindakan setiap departemen hanya mempersiapkan kebutuhan permintaan tamu event wedding dan pengawasan dalam hal ini hanya dikukan oleh pihak Sales marketing Hotel saja.

Disimpulkan bahwa penerapan manajamen banquet dalam menangani event wedding di Hotel Pangeran Beach Kota Padang mengenai planning secara umum dapat dikategorikan cukup baik hal ini terlihat dari Perencanaan dalam menentukan waktu dan tempat wedding hanya direncanakan oleh tamu wedding dan perencanaan mengenai tim kerja pihak hotel ada sudah direncanakan dengan baik, pengorganisasian tugas dan tanggung jawab mengenai pembentukan tim kerja dari pihak hotel sudah berjalan dengan baik, tindakan dalam menentukan tim kerja sudah berjalan dengan baik, pengawasan dari pimpinan sendiri mengenai tim kerja sudah dilaksanakan dengan baik.

Disimpulkan bahwa penerapan manajamen banquet dalam menangani event wedding di Hotel Pangeran Beach Kota Padang mengenai coordination secara umum dapat dikategorikan sangat baik hal ini terlihat dari Perencanaan dalam koordinasi ini sendiri sudah direncanakan dengan baik, pengorganisasian tugas dan tanggung jawab sudah berjalan dengan baik, tindakan mengenai partisipasi setiap departemen sudah dilaksanakan dengan baik dan pengawasan dari setiap pimpinan departemen Hotel sudah dilaksanakan.

Disimpulkan bahwa penerapan manajamen banquet dalam menangani event wedding di Hotel Pangeran Beach Kota Padang mengenai evaluation secara umum dapat dikategorikan sangat baik hal ini terlihat dari Perencanaan evaluasi setelah event wedding sudah 
direncanakan dengan baik oleh setiap departemen hotel, pengorganisasian tugas dan tanggung jawab setiap pimpinan departemen dalam melakukan evaluasi sudah dilaksanakan dengan baik, tindakan pimpinan setiap departemen dalam melakukan evaluasi setelah event wedding sudah dijalankan dengan baik dan pengawasan dalam melakukan evaluasi ada dilakukan dalam setiap departemen.

\section{Saran}

Hasil penelitian ini akan menjadi gambaran untuk setiap departemen yang menangani event wedding dan diharapkan dapat menjadi masukan untuk mengetahui manajemen (Perencanaan, Pengorganisasian, Pelaksanaan dan Pengawasan) dan dapat mengembangkan perencanaan khususnya dalam melakukan riset, sebaiknya pihak Hotel melakukan riset mengenai kebutuhan, harapan, dan keinginan konsumen sebelum melaksanakan event wedding agar dapat mengetahui trend yang sedang terjadi dan akan menjadi kelebihan untuk bersaing dengan Hotel-hotel yang ada di Kota Padang. Kepada Jurusan Pariwisata disarankan untuk dapat menambah dan melengkapi buku referensi diperpustakaan yang berkaitan dengan manajemen banquet sehingga dapat mempermudah mahasiswa dalam penulisan skripsi ataupun karya ilmiah lainnya. Bagi peneliti berikutnya agar dapat meneliti tentang manajemen atau pemasaran event dalam bentuk pembahasan yang mengarah pada bentuk metode kuantitatif sehingga harapannya dapat membantu perluasan referensi dalam meneingkatkan kualitas pelaksanaan event.

Catatan: artikel ini disusun berdasarkan skripsi penulis dengan Pembimbing

\section{DAFTAR PUSTAKA}

Arikunto, 2007. Prosedur Penelitian suatu Pendekatan Praktik. Jakarta: Rineka Aksara.
,2009.

Dasar-dasar

Evaluasi

Pendidikan, Edisi Revisi. Jakarta: Bumi Aksara.

Goldblatt, Joe. 2002. Special Events. Third Edition. New York: John Wiley and Sons.

R. Terry, George. 2006. Prinsip-Prinsip Mana

Riyadi, Heru. 2015. Pengetahuan Layanan Makanan dan Minuman.

Bandung: Alfabeta

Rumekso. 2001. Housekeeping Hotel. Yogyakarta: Andi. 